\title{
Complex responses to invasive grass litter by ground arthropods in a Mediterranean scrub ecosystem
}

\author{
Elizabeth Mary Wolkovich • Douglas T. Bolger • \\ David A. Holway
}

Received: 21 April 2009 / Accepted: 7 July 2009 / Published online: 8 August 2009

(C) The Author(s) 2009. This article is published with open access at Springerlink.com

\begin{abstract}
Plant invasions have tremendous potential to alter food webs by changing basal resources. Recent studies document how plant invasions may contribute to increased arthropod abundances in detritus-based food webs. An obvious mechanism for this phenomenon-a bottom-up effect resulting from elevated levels of detritus from the invasive plant litter-has not been explicitly studied. We examined the effects of an annual grass invasion on ground arthropod assemblages in the coastal sage scrub (CSS) of southern California. Bottom-up food web theory predicts that the addition of detritus would increase generalist-feeding arthropods at all trophic levels; accordingly, we expected increases in fungi, Collembola, and common predators such as mites and spiders. For the common ant taxa, habitat alteration may also be important for predicting responses. Thus we expected that Forelius mccooki and Pheidole vistana, the most common ant species, would
\end{abstract}

Communicated by Nathan Sanders.

Electronic supplementary material The online version of this article (doi:10.1007/s00442-009-1425-7) contains supplementary material, which is available to authorized users.

E. M. Wolkovich $(\bowtie) \cdot$ D. T. Bolger

Environmental Studies Program, Dartmouth College,

6182 Steele Hall, Hanover, NH 03755, USA

e-mail: e.wolkovich@ dartmouth.edu

E. M. Wolkovich

Department of Biological Sciences, Dartmouth College, 6044 Gilman, Hanover, NH 03755, USA

D. A. Holway

Division of Biological Sciences, University of California,

San Diego, 9500 Gilman Drive, La Jolla, CA 92093-0116, USA decline because of changes in soil temperature (F. mccooki) and habitat structure $(P$. vistana) associated with litter. We studied trends observationally and conducted a 3-year experiment in which we manipulated litter quantity. In contrast to other published studies, most detritus-based arthropod taxa declined in areas of high grass invasion, and, within trophic levels, responses often varied idiosyncratically. For the two most common taxa, a native ant (F. mccooki), and predatory mites in the Anystidae, we experimentally linked declines in abundance to increased levels of invasive grass litter. Such declines, especially those exhibited by the most common ant taxa, could have cascading effects on the CSS ecosystem, where ants are numerically dominant and thus may have broad influences on food web and ecosystem properties. Our results highlight that accurately predicting arthropod responses to invasive plant litter requires careful consideration of the structural and food resources provided by detritus to each particular food web.

Keywords Detritus · Food web · Coastal sage scrub · Bottom-up · Habitat structure

\section{Introduction}

Invasive species can transform the habitats they colonize by altering a suite of ecosystem properties (Mack et al. 2000). Invasion by a single species can initiate a cascade of changes in other trophic levels, drastically altering food web composition and structure from the pre-invasion state (O'Dowd et al. 2003; Sakai et al. 2001). Plant invasions in particular, and the associated declines in numerically dominant native plant species, may alter communities via both their living and dead (litter) plant matter. 
Numerous studies have shown that plant invasions generally increase basal resources through dramatic increases in living plant biomass and litter (Liao et al. 2008). Bottom-up food web theory predicts this increase would in turn increase abundance of species in all trophic levels linked to these basal resources (Oksanen et al. 1981). In agreement with theory, recent studies have found that, compared to uninvaded areas, invaded areas have similar detrital food web composition with increased abundance of arthropods at all trophic levels (Gratton and Denno 2005; Kappes et al. 2007), and, for one system, stable isotope studies indicate that a bottom-up effect of detritus contributes to these changes (Gratton and Denno 2006). In contrast, grazing webs show reduced species and functional group richness and gross declines in abundance across trophic levels (Ernst and Cappuccino 2005; Gratton and Denno 2005), suggesting that grazers respond to the change in food plants more than to the altered productivity of the system.

However, several features of these studies limit their generalization. First, observational studies (Ernst and Cappuccino 2005; Gratton and Denno 2005; Kappes et al. 2007) examine landscapes undergoing concurrent changes, such as increased fire frequency or $\mathrm{N}$ deposition, together with invasion (Didham et al. 2005, 2007). These methodological limitations may obscure any clear link of invasion to food web changes, and especially to a bottom-up effect of invasive plant litter. Second, studies have been conducted mainly in submersed systems-floodplains and salt marshes (Gratton and Denno 2005, 2006; Kappes et al. 2007)-thus their applicability to terrestrial systems is unknown.

We studied the effects of invasive plant litter in coastal sage scrub (CSS) ecosystems in southern California, a semi-arid system extensively invaded by non-native annual European grasses (Minnich and Dezzani 1998). This invasion, similar to others in semi-arid systems, is associated with an altered fire regime (Keeley et al. 2005) and dramatic landscape changes (Cione et al. 2002): uninvaded CSS is shrub-dominated with extensive bare ground and soil crusts (Mooney 1977), while invaded areas transform to a landscape of shrubs imbedded within a matrix of nonnative annual grasses (Cione et al. 2002). The invasion of annual grasses, a plant functional type distinct from the dominant shrubs, produces a striking change in basal resources: invaded CSS habitat is four times more productive, has 50 times more litter and 30\% higher concentrations of soil nitrogen compared to uninvaded habitat (Wolkovich et al. 2009). Thus, the invasion has created the potential for significant bottom-up effects. In contrast to other invaded systems, increased productivity in CSS translates into elevated abundances of arthropod herbivores and predators on native shrub (Wolkovich 2009). Here we study whether the detritus-based ground arthropod community also exhibits a simple bottom-up response to invasion.

\section{Hypotheses and predictions}

Plant invasions that increase a system's litter produce two notable changes affecting arthropod communities: increased basal resources and habitat alteration, including microclimatic and structural changes. Such changes may be particularly dramatic when-as in CSS-the invasion results in a dramatic change in the life form of the dominant plant species and disturbance regime. We examined such possible changes by conducting a 1-year observational study followed by a 3-year manipulation of invasive grass litter. Bottom-up food web theory predicts that the addition of abundant detritus would increase generalist arthropod taxa at all trophic levels in CSS. We expected that grass litter would increase fungi because of its high $\mathrm{C}: \mathrm{N}$ ratio (Wardle et al. 1999, 2004). We expected Collembola, considered generalist fungivores (Hunt et al. 1987), to track the increase in fungal resources and in turn subsidize predator abundance: spiders (Araneae), harvestmen (Opiliones) and Prostigmata mites (Dindal 1990; Wise 1993). In contrast, ants are known to respond strongly to habitat alteration, especially changes to the thermal environment (Andersen 1997; Retana and Cerda 2000), as well as to food resources. Furthermore, of the dominant arthropod taxa in this system, only ants are described sufficiently well taxonomically and ecologically (Menke and Holway 2006) to develop specific predictions based upon the habitat alteration hypothesis. Thus, for the five most common native ant species, we based predictions on dietary preferences, morphology, and environmental tolerances. We expected that Pheidole vistana, a gracile species restricted to open arid and semi-arid habitats (Creighton 1950; Wheeler and Wheeler 1986), would have difficulty moving through dense litter as a result of its larger body and long legs. Forelius mccooki, a species tolerant of high temperatures (Holway et al. 2002), may decline in areas of high grass invasion as a result of decreased soil surface temperatures caused by the insulating effect of grass litter (Wolkovich et al. 2009). Because Pheidole clementensis and Solenopsis xyloni are known to harvest non-native seeds (Gregg 1969), we predicted they would increase in response to the addition of non-native grass litter. Unlike P. clementensis, S. xyloni has a much wider geographical range and occurs in a wide variety of habitats (Creighton 1950; Ward 2005). For this reason we expected that this species would exhibit more flexible responses to leaf litter additions. Lastly, Solenopsis molesta is a klepto-parasite of other ant species and, like S. xyloni, occurs in a wide variety of environments; thus we predicted it would respond to grass invasion in a manner similar to that of the other common ant species. 


\section{Materials and methods}

Study system and site

We conducted all work in CSS habitat of the San Diego National Wildlife Refuge, Sweetwater Unit (N32 $43^{\prime} 15^{\prime \prime}$ W116 $57^{\prime} 15^{\prime \prime}$, hereafter Sweetwater). CSS is a droughtdeciduous shrub habitat, which at this site is co-dominated by Artemisia californica and Eriogonum fasciculatum (Schoenherr 1992). Although the exact fire history at Sweetwater is unknown, the site contains mature CSS so we presume fire has not been widespread at the site within the last 20 years.

Non-native annual European grasses invaded much of CSS habitat in the last century (Minnich and Dezzani 1998). Dominant non-native grasses in the study area include Brachypodium distachyon, Bromus madritensis ssp. rubens and Avena barbata. Other non-native annual grasses present include Avena fatua, Bromus hordeaceus, Bromus diandrus, Gastridium ventricosum, and Vulpia myuros. Native grasses at the site include the perennials Nasella lepida, and N. pulchra, together with Vulpia octoflora - the only native annual grass we found.

\section{Observation}

In 2004 we collected data on vegetation and ground arthropods across a gradient of non-native grass cover. We centered $2 \times 2 \mathrm{~m}$ plots around Artemisia californica shrubs (all approximately $1 \mathrm{~m}^{3}$ ), across three different slope (east, north, south) aspects. We visually estimated invasive grass cover (to the nearest $0.01 \mathrm{~m}^{2}$ ) in each $4-\mathrm{m}^{2}$ plot, constraining cover to a maximum of $100 \%$ (Barbour et al. 1999). Arthropods were pitfall-trapped as described below.

\section{Experiment}

We conducted a two-factor invasive grass litter experiment in 2005 and 2006, and followed effects through 2007 (Wolkovich et al. 2009). We established $3 \times 3 \mathrm{~m}$ (separated by $10-50 \mathrm{~m}$ ) experimental plots around typically sized $\left(\sim 1 \mathrm{~m}^{3}\right)$ Artemisia californica shrubs. Working in areas either highly invaded by grass $(>40 \%$ non-native grass cover, assessed visually) or not $(<5 \%$; factor 1 , Invasion level), we added grass litter (to two times the naturally high abundance for each particular year, i.e., the amount varied due to annual conditions), left litter levels unchanged (control), or removed all grass litter (factor 2: Litter: Addition, Control, Removal) in a fully crossed design for a total of six treatments (Invasion level $\times$ Litter), with eight replicates in each experimental group. We located plots in patches of High and Low Invasion that were well-interspersed and assigned litter treatments to selected plots randomly (for further details, see Wolkovich et al. 2009). In 2005, after the manipulation, all Addition plots had $\sim 543 \mathrm{~g} \mathrm{~m}^{-2}$ non-native grass litter $\left(543 \mathrm{~g} \mathrm{~m}^{-2}\right.$ added to Low Invasion $\times$ Addition plots, $271.5 \mathrm{~g} \mathrm{~m}^{-2}$ added to High Invasion $\times$ Addition plots), and we added an additional $68 \mathrm{~g} \mathrm{~m}^{-2}$ to all Addition plots in 2006. In removal plots, we cut all non-native grass litter to within $2 \mathrm{~cm}$ of ground level and removed it from the plots. We additionally had one High Invasion $\times$ Removal control treatment (again with eight replicates, for a total of 56 plots) to test for effects of the manipulation such as trampling and cutting: we cut all litter, removed it, then immediately returned it to the plot [see electronic supplementary material (ESM) Table S1 showing that removal controls did not differ significantly from controls].

\section{Soil fungi}

At the end of the experiment we measured soil fungal biomass in a subset of plots as a proxy for fungi available to ground arthropods. We used a soil assay because there is no standard assay for measures of litter fungi and because litter importantly contributes to soil resources (Coleman and Crossley 2003). We collected soil cores (10 cm deep by $3 \mathrm{~cm}$ diameter) in March 2007 from a subset of plots (24 total, 3-5 randomly selected replicates from all except Low Invasion $\times$ Removal treatments). We placed samples immediately on ice and shipped them to Soil Food Web Inc. (Corvallis, OR) for direct counts and bio-volume analyses of total fungi (Ingham et al. 1986a, b).

\section{Arthropod sampling}

We sampled the ground arthropod community with pitfall traps, which have been previously used in CSS (Bolger et al. 2000; Holway 2005). Pitfall trap captures represent an integrated measure of abundance and activity, which makes absolute numerical comparisons difficult, especially among taxa. However, pitfall traps are an excellent method to accomplish our goal of comparing the effects of grass litter cover within taxa because they are repeatable and sample across several days and nights (Curtis 1980; Perner and Schueler 2004), and do not require destructive sampling of the experimental plot. We set two $50 \mathrm{ml}$ plastic tubes $(3 \mathrm{~cm}$ diameter), filled with $20 \mathrm{ml}, 1: 1 \mathrm{mix}$ of water:propylene glycol, in established permanent plastic sleeves set flush with the ground and $1 \mathrm{~m}$ apart under each plot's central Artemisia californica shrub. Preliminary analyses suggest that these smaller pitfall traps capture a similar composition of arthropods compared to traps with $9 \mathrm{~cm}$ diameter, but have far lower rates of accidental vertebrate capture (D. Bolger and E. Wolkovich, unpublished data). 
We sampled before and after the manipulation, from 2005 to 2007, as well as in 2004. In each year we opened pitfalls twice: once in the mid-growing season (late March) and once in the late-growing season (May). Because we generally captured different taxa in each period (Collembola and other detritivores in mid-season, ants primarily in late season), we summed data within a year for analyses. We generally opened traps for 4-day periods twice each year. However in the first trapping session in 2004 we collected for only 2 days, and in the late season sampling in 2006 we increased this to 8 days and continued this through all of 2007 sampling. We therefore adjusted all arthropod numbers to a season-long mean based on a total of 8 days per season (i.e., two 4-day periods). We sorted all arthropods $>0.5 \mathrm{~mm}$ to order, and additionally sorted Collembola and mature spiders to family, and ants to species.

\section{Statistical analyses}

We analyzed all arthropod taxa for which we developed specific predictions. These were Collembola (families: Entomobryidae, Isotomidae, Sminthuridae); the native ants F. mccooki, P. clementensis, P. vistana, S. molesta, and S. xyloni, Prostigmata mites, spiders and harvestmen. These taxa represented $69 \%$ of all arthropods captured numerically in 2004, 59\% in 2005 and $79-80 \%$ in 2006-2007. For all analyses we pooled pitfalls by plot and year resulting in one adjusted mean that represents the average number of individuals captured by a pitfall trap open for 8 days, although traps were often open longer than this each year (see above).

In 2004 we analyzed only a subset of these taxa because of low sampling effort. Further, data for many taxa showed highly non-normal distributions. For three species of ants (F. mccooki, P. vistana and S. xyloni), each of which had a high number of zeros, we fit a zero-inflated Poisson general linear regression. For the remaining taxa we fit models using either a negative binomial (mites, spiders) or a Gaussian distribution ( $\log _{10}$ transformed total arthropods). We used residual plots, over-dispersion values, and Akaike's Information Criterion (AIC) values to assess that these were the best models for each taxa.

To assess overall changes in community composition in response to the experiment we used permutational (PER)MANOVA and non-metric multi-dimensional scaling (NMDS). PERMANOVA is similar to traditional parametric multivariate analysis of variance (MANOVA) in simultaneously testing multiple response variables to factors. It differs in that it relaxes the assumption of a multivariate normal distribution by converting data to dissimilarity measures, then obtaining a pseudo- $F$ statistic by expectations of mean squares and a $P$-value based on permutations of the data (Anderson 2001). We fitted a model to our two-factor design for each year using Bray-Curtis similarity on square-root transformed data with 9,000 permutations. For both PERMANOVA and NMDS we examined tests including all taxa considered here versus only those with few zeros; results were similar, thus we present the analysis on all taxa here.

Because we had pre-manipulation (2005) and postmanipulation (2006-2007) data, we further analyzed experiment results with a two-way repeated measures ANOVA testing for effects of Invasion level (High or Low), Litter (Addition, Control, Removal) and their interaction (see ESM Table S2). We used an unstructured variance-covariance matrix (Wolfinger 1996) for all taxa because it was a significantly better fit to all taxa than a compound symmetry matrix, as assessed by AIC. To meet assumptions of the tests we square-root transformed all arthropod data, but report back-transformed means and standard errors unless otherwise mentioned. For the ant species $F$. mccooki, the square-root transformation improved but did not remove large variance differences between High and Low Invasion level plots; however, because we had nearly equal sample sizes for the manipulation (eight for all except high removals, for which we have eight in 2005, seven in 2006-2007) the tests should be fairly robust to deviations from equal variance (Box 1954). For total arthropods we used a $\log _{10}$ transformation to normalize the data in all years. Because we had only 1 year of data for soil fungi and an incomplete set of treatments (i.e., no Low Invasion $\times$ Removal), we performed a two-way ANOVA, excluding High Invasion $x$ Removal. Analyses on spiders alone were extremely similar to analyses of spiders and harvestmen together; thus, we report only the latter analyses. We conducted all tests in $\mathrm{R}$ (version 2.5.1), using packages nlme, MASS, pscl and vegan (R Development Core Team 2007).

\section{Results}

We sorted a total of 21,217 arthropods from 13 orders (Acari, Araneae, Archaeognatha, Collembola, Coleoptera, Diptera, Hemiptera, Hymenoptera, Lepidoptera, Neuroptera, Orthoptera, Pscoptera, and Siphonaptera) collected from pitfall traps over 4 years of sampling. We collected 15 native ant species (Table 1); the five major species for which we developed hypotheses represented 77-93\% (depending on year) of all native ants collected. F. mccooki was the most common ant in all 3 years of the manipulation (Table 1), while $P$. vistana and $S$. xyloni were alternately the second most common ant species (Table 1). Ants were the most common taxa collected in 2007, while entomobryid and isotomid collembolans were most common in 2005-2006 (Table 2). 
Table 1 Ant species and the percent they represent of all ants collected in pitfall traps each year during the course of our 3-year nonnative litter manipulation

\begin{tabular}{lrrr}
\hline Species & $\begin{array}{c}2005 \\
(\%)\end{array}$ & $\begin{array}{l}2006 \\
(\%)\end{array}$ & $\begin{array}{l}2007 \\
(\%)\end{array}$ \\
\hline Crematogaster californica & 4.6 & 3.7 & 3.3 \\
Dorymyrmex insanus & 0.6 & 0.3 & 0.8 \\
Forelius mccooki & 36.2 & 31.6 & 42.9 \\
Messor andrei & 0.4 & 0.4 & 0.3 \\
Myrmecocystus mimicus & 4.0 & 0.8 & 1.3 \\
Neivamyrmex nigrescens & 0.0 & 0.6 & 0.0 \\
Paratrechina sp. c.f. terricola & 0.6 & 0.6 & 0.7 \\
Pheidole clementensis & 5.6 & 2.5 & 4.5 \\
Pheidole vistana & 16.0 & 23.9 & 27.1 \\
Tapinoma sessile & 0.0 & 0.5 & 0.6 \\
Temnothorax andrei & 0.8 & 0.3 & 0.6 \\
Tetramorium spinosum & 0.2 & 0.9 & 0.0 \\
Solenopsis amblychila & 10.0 & 0.1 & 0.1 \\
Solenopsis molesta & 2.0 & 4.7 & 8.3 \\
Solenopsis xyloni & 16.8 & 28.6 & 9.4 \\
\hline
\end{tabular}

Table 2 Ground arthropod taxa studied and the percent of total arthropods collected in pitfall traps each year of the experiment

\begin{tabular}{llcc}
\hline Taxa & $\begin{array}{l}2005 \\
(\%)\end{array}$ & $\begin{array}{l}2006 \\
(\%)\end{array}$ & $\begin{array}{l}2007 \\
(\%)\end{array}$ \\
\hline $\begin{array}{l}\text { Entomobryidae and } \\
\quad \text { Isotomidae Collembola }\end{array}$ & 19.9 & 25.8 & 17.5 \\
Sminthuridae Collembola & 2.0 & 3.1 & 13.1 \\
Anystidae Acari (mites) & 6.3 & 13.8 & 12.6 \\
Non-Ansytidae Acari (mites) & 7.6 & 11.5 & 10.2 \\
Araneae (spiders) and & 8.9 & 2.7 & 2.6 \\
$\quad$ Opiliones (harvestmen) & & & \\
Formicidae (ants) & 19.1 & 25.5 & 24.5 \\
\hline
\end{tabular}

Spiders were predominantly from the families Lycosidae, Salticidae, Scytodidae, and Thomisidae, with Scytodidae (all Scytodes sp. \#1, Prentice et al. 1998) and Salticidae, each representing $\sim 20 \%$ of all spiders collected most years. Prostigmata mites from the Anystidae family were the most common mites, and we thus analyzed them separately from other Prostigmata mites (many from the Erythraeidae family). The common non-native arthropods in CSS, Oecobius annulipes (spider) and the Argentine ant (Linepithema humile) — the only non-native ant species we encountered-were rare (less than 1 individual in any year).

\section{Observation}

Overall arthropod abundance declined with increasing levels of grass cover (Fig. 1a), not supporting bottom-up predictions of a whole food web increase. The ants $F$. mccooki and $P$. vistana followed predictions, declining with increasing non-native grass cover (Fig. 1b, c); Prostigmata mites also declined (Fig. 1d).

\section{Experiment}

As in our observational survey, fewer total arthropods (Fig. 2) were captured in areas with high levels of grass cover (Invasion level, $F_{2,42}=12.17, P<0.0001$ ), though this effect varied by year (Invasion level $\times$ Year: $F_{2,82}=$ $10.13, P<0.0001)$. Abundances also varied by year alone (Year, $F_{2,82}=12.34, P<0.0001$ ). In 2005 (pre-manipulation) High Invasion plots had $34 \pm 1.2$ (mean \pm SE) arthropods collected per season, versus $50 \pm 1.1$ in Low Invasion plots. In 2006 we collected most arthropods, and High Invasion plots were again lower $(49 \pm 1.1$ vs $97 \pm 1.1$ ). Two years post-manipulation (2007), arthropod abundances were also relatively high, but roughly similar between High and Low Invasion plots $(60 \pm 1.1$ vs $66 \pm 1.1)$.

Arthropod community composition also varied due to non-native grass cover throughout the experiment (PERMANOVA: Invasion level for all 3 years: $F_{1,41}>5.86$, $P<0.001$ ) with a separation apparent before (Fig. 3a) and after (Fig. 3b) the experiment. Manipulation of grass litter marginally affected the community (Litter treatment before manipulation: $F_{2,41}=1.20, P=0.29,1$ year after: $F_{2,41}=$ $1.74, P=0.050,2$ years after: $F_{2,41}=1.74, P=0.062$ ). The effect of treatment varied by Invasion level 1 year $\left(F_{2,41}=2.04, P=0.020\right)$ but not 2 years $\left(F_{2,41}=1.51\right.$, $P=0.12$ ) after manipulation. Differences in community composition due to grass invasion over all years (Fig. 3a, b) and responses by the community following the manipulation (Fig. 3b) appear to have been driven by specific taxa, which we now discuss in turn.

As predicted, soil fungal biomass was greater in High Invasion plots $\left(F_{1,14}=9.04, P=0.009\right.$, Fig. 4 a) but did not vary with respect to the Litter treatment $\left(F_{2,14}=0.39\right.$, $P=0.55$, Fig. 4a). Collembola responses varied by family: the most common Collembola, entomobryids and isotomids, were captured less often in High Invasion plots $\left(F_{1,42}=6.64, P=0.014\right.$, Fig. $4 \mathrm{c}$, see also ESM Table S2) but did not respond to the litter manipulation $\left(F_{4,82}=1.24\right.$, $P=0.30$ ). Sminthurid collembolans, however, which we collected in large numbers only in 2007 , showed a complex response to invasion and litter $\left(F_{4,82}=4.61, P=0.002\right.$, Fig. 4b). In 2007, numbers were greater overall in High Invasion plots (Fig. 4b) and varied by litter manipulation $\left(F_{4,82}=3.95, P=0.006\right)$. Sminthurid collembolans tended to decrease in litter removal plots (Fig. 4b) but also tended to decline with addition of litter in Low Invasion plots only (Fig. 4b, Invasion level $\times$ Litter $\times$ Year: $F_{4,82}=4.61$, 
Fig. 1 Relationships between percent non-native grass litter cover and total arthropods (a), two ant species $(\mathbf{b}, \mathbf{c})$, and predatory mites $(\mathbf{d})$ in 2004 from our observational study along a gradient of non-native grass cover. For Total arthropods $t_{1,27}=25.33, P=0.019$; for Forelius mcco$o k i$, without outlier (as shown): $z_{1,26}=6.46, P<0.0001$, with outlier (not shown): $z_{1,27}=-6.29, P<0.0001$; for Pheidole vistana: without outlier (as shown): $z_{1,26}=-3.18, P=0.002$, with outlier (not shown): $z_{1,27}=-8.88, P<0.0001$; for mites: $z_{1,27}=16.10, P=0.07$. Arthropod values are the total number of individuals trapped in each growing season adjusted to four traps per plot opened for 8 days (see "Materials and methods" for further details)

$P=0.002)$. These collembolans increased with increased fungal biomass $\left(F_{1,22}=5.07, P=0.04\right)$.

Predator groups showed divergent responses to the litter treatments, though none supported bottom-up theory. All mites (Anystidae and other prostigmatids) were greater in Low Invasion plots (Anystidae: $F_{1,42}=22.66, P=0.001$, non-Anystidae: $F_{1,42}=51.52, \quad P<0.0001 \quad F i g .4 \mathrm{~d}, \quad$ e), although for Anystidae mites the magnitude of this trend varied by year $\left(F_{2,82}=3.21, P=0.046\right.$, Fig. 4 d). Anystidae mites additionally responded to the litter manipulation $\left(F_{4,82}=5.32, P=0.001\right)$; trends contrasted with our predictions: mite numbers decreased with litter addition and increased with litter removal (Fig. 4d). Spiders and harvestmen responded variably across years to grass invasion during the experiment, but did not respond to the litter manipulation $\left(F_{4,82}=0.44, P=0.78\right.$, Fig. $\left.4 \mathrm{f}\right)$.

Ant species, in general, followed our predictions. $F$. mccooki and $P$. vistana abundances were lower in High Invasion plots $\left(F . m c c o o k i, F_{1,42}=18.21, P<0.0001\right.$, $P$. vistana, $F_{1,42}=19.80, P<0.0001$, Fig. 5a, b). $P$. vistana exhibited a pre-manipulation trend that varied by Litter treatment $\left(F_{2,42}=4.66, P=0.015\right)$. In contrast to $F$. mccooki and $P$. vistana, numbers of $P$. clementensis were greater in High Invasion plots in all years $\left(F_{1,42}=8.16, P=0.007\right.$, Fig. 5c). Only $F$. mccooki responded to the litter manipulation $\left(F_{4,82}=2.55, P=0.045\right)$, and the response followed our predictions: captures of this species increased with litter removal and decreased with litter addition (Fig. 5a). Solenopsis were not consistently affected by grass invasion or the litter manipulation (Fig. 5d,e, ESM Table S2). Solenopsis xyloni showed significant effects of treatment by grass amount $\left(F_{4,82}=2.59, P=0.043\right)$, but its responses followed no biologically interpretable pattern (Fig. 5e).

\section{Discussion}

Despite the great increase in plant productivity and soil nutrients caused by grass invasion we did not find convincing evidence of a bottom-up effect on ground arthropods. We found that arthropod taxa responded to non-native grass
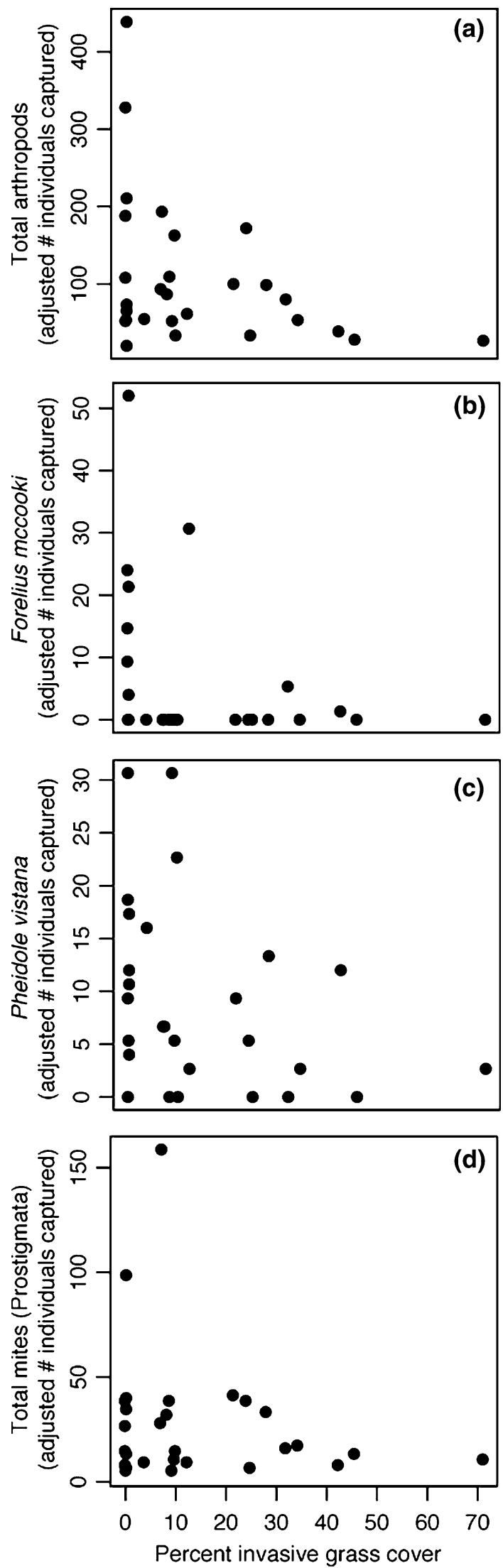


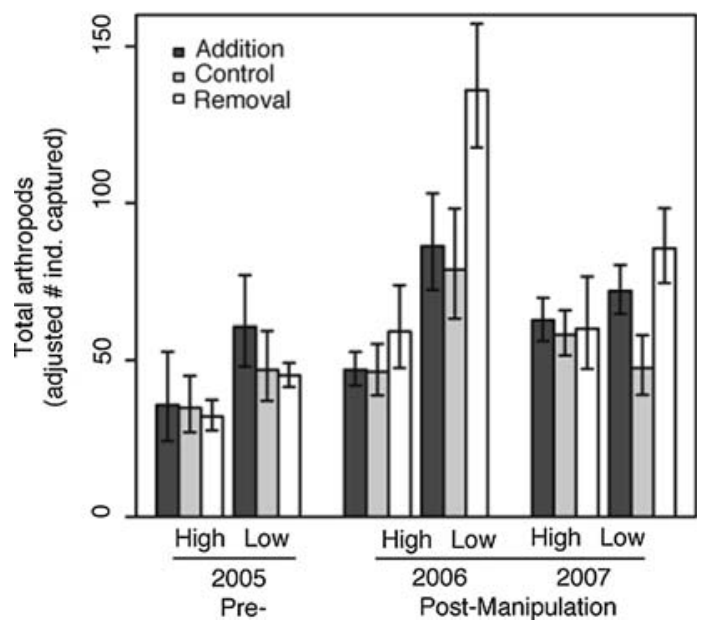

Fig. 2 Total arthropods collected by pitfall-trapping during our 3 year non-native grass litter manipulation. 'High' and 'Low' refer to premanipulation Invasion level, while 'Addition,' 'Control,' and 'Removal' refer to the Litter treatment. Bars Mean \pm SE. Arthropod values are the total number of individuals trapped in each growing season adjusted to four traps per plot opened for 8 days (see "Materials and methods" for further details)

invasion in differing ways, which in some cases we can link to taxon-specific behavioral, morphological, and dietary characteristics. As predicted, invasive grass litter increased fungal resources; however, this effect did not produce a positive bottom-up effect on the detritus-based ground arthropod community. Further, some of the most common taxa, F. mccooki and Anystidae mites, consistently declined following additions of non-native grass litter. These decreases contrast with the responses of shrub arthropods on these same plots, which exhibited a strong bottom-up response (Wolkovich 2009).

Our results provide an interesting contrast to previous studies of detritus-based arthropod food webs in systems undergoing plant invasions, and highlight that responses may be due to the properties of detritus both as a food resource and as a habitat modifier. Our surprising findings may result, in part, from the novel habitat complexity that invasive grasses introduce to semi-arid CSS. While other studies have found increased abundance of arthropods in detrital webs (Ernst and Cappuccino 2005; Gratton and Denno 2005, 2006; Kappes et al. 2007), we found that the majority of arthropod taxa were consistently less abundant in areas of high non-native grass cover. Grass invasion into CSS dramatically changes the physical structure near the soil surface for ground arthropods: areas once dominated by bare ground and soil crusts, with low litter resources, become dense grass stands with high loads of litter yearround (Wolkovich et al. 2009). Therefore, arthropod taxa may decline because they lack the ability to move or forage easily in this novel structure or because they may be unable to use the litter as a food resource, or to tolerate the altered
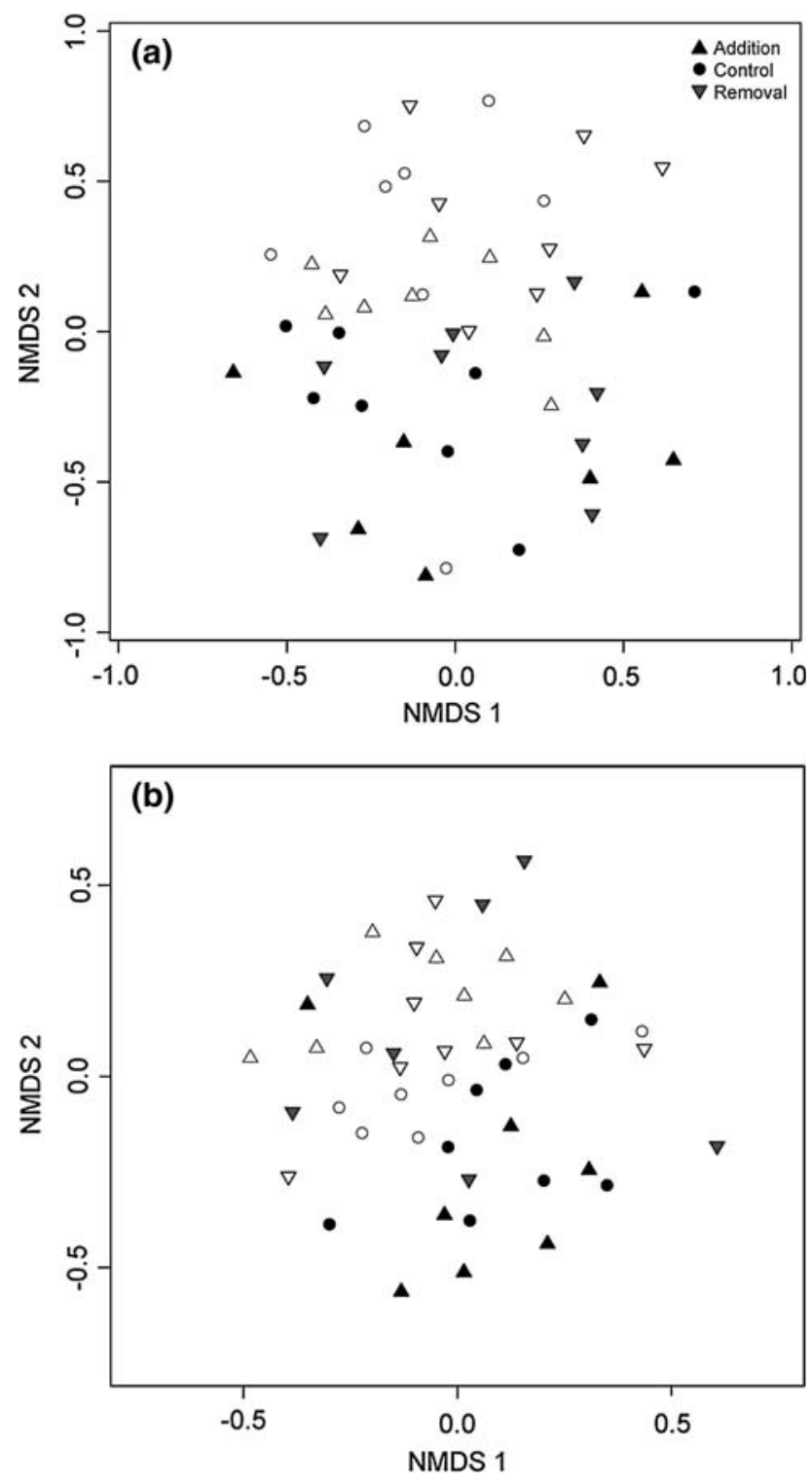

Fig. 3 Non-metric multi-dimensional scaling (NMDS) plots of pitfall arthropod community in 2005, before the grass litter manipulation (a) and 2007, 2 years after the manipulation (b). Filled and open symbols represent areas of high and low grass invasion, respectively

microclimate. Additionally, CSS detrital webs are highly ant-dominated (Longcore 1999), unlike previous studies in other systems (Gratton and Denno 2005, 2006; Kappes et al. 2007). Complex trophic interactions between ants, spiders, and Collembola, as documented in other systems (Moya-Larano and Wise 2007; Sanders and Platner 2007), may occur in CSS and attenuate bottom-up effects (Polis and Strong 1996).

We found little evidence of bottom-up responses to the additional food resource that invasive grass litter provided; instead species appeared to respond in a taxon-specific manner to grass invasion and to our litter manipulation. Non-native grass litter is of much lower quality (based on 
Fig. 4 Responses by fungi (a), collembolan families $(\mathbf{b}, \mathbf{c})$ and non-ant predators $(\mathbf{d}-\mathbf{f})$ to a 3 year non-native grass litter manipulation. Note for fungi (a) we did not collect data for 2005 2006 nor for the Low Invasion $\times$ Removal treatment in 2007. Bars are mean \pm SE. Legend as in Fig. 2. Arthropod values are the total number of individuals trapped in each growing season adjusted to four traps per plot opened for 8 days (see "Materials and methods" for further details)
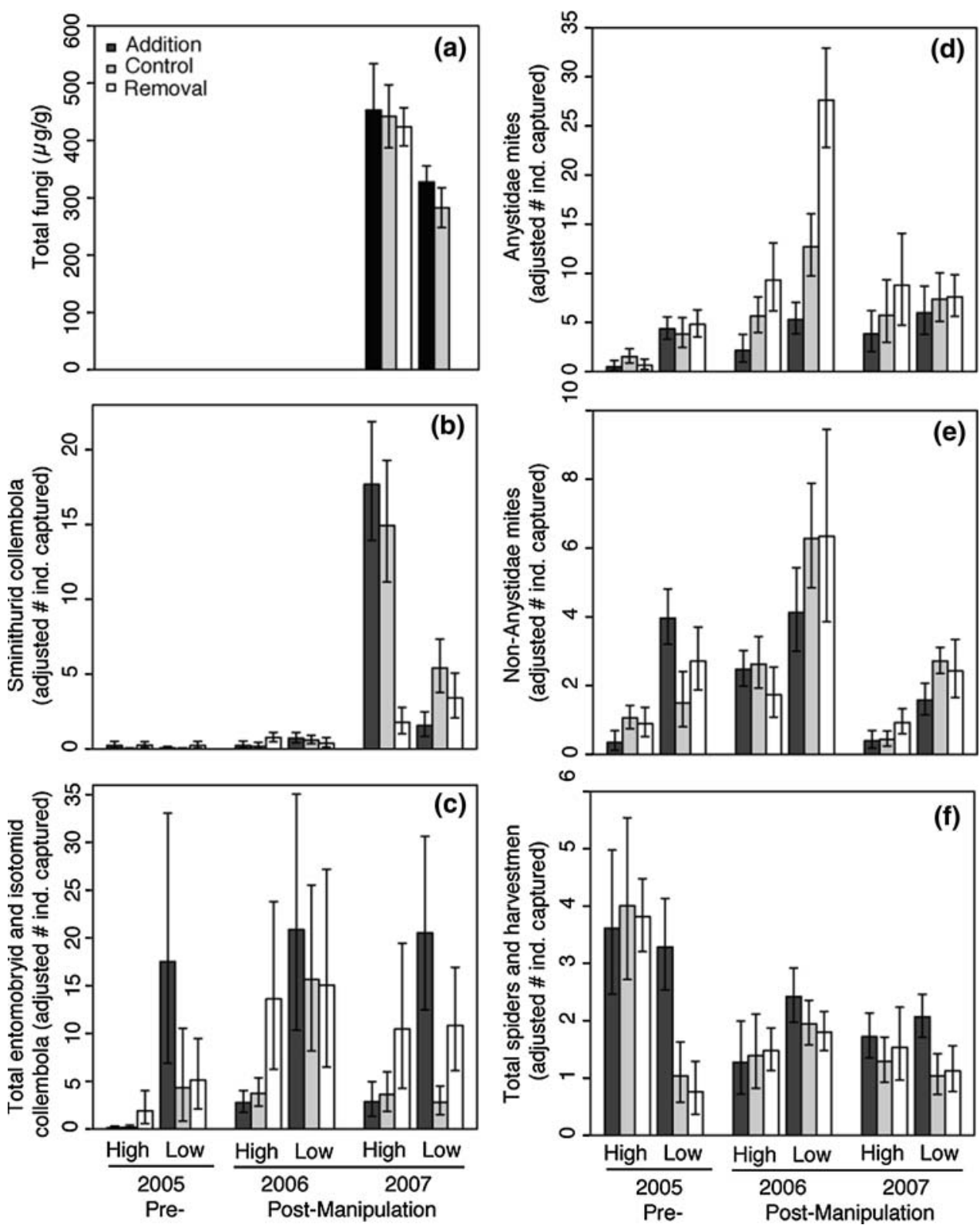

its $\mathrm{C}: \mathrm{N}$ ratio) compared to native shrub litter (Wolkovich et al. 2009), and these differences should lead to increased fungi and fungal feeders (Wardle 2002). However, we found that Collembolan families, often considered generalist fungivores (Coleman and Crossley 2003; Hunt and Wall 2002), responded disparately, indicating that responses may be idiosyncratic or possibly that Collembola may be more specialized in terms of their resource preferences than traditionally thought (Coleman and Crossley 2003). The two most common families in CSS (Entomobryidae and Isotomidae) declined in invaded areas, which had greater fungal abundance, while the taxa in the Sminthuridae family increased. If densities of Collembola are driven by bottomup forces, they may be responding to fine-scale variation in the availability of certain taxa of fungi, or they may be feeding on other taxa (e.g., protozoa, nematodes; Lensing et al. 2005). Alternatively, changes in the density of different Collembola families may be the result of microclimatic changes caused by the presence of grass litter: other studies that manipulated thatch and microclimate have found that small arthropods respond mainly to changes in microclimate (Coleman and Crossley 2003; Gill 1969). As in many ground food webs, Collembola make up a large component of the CSS detritus-based arthropod community. Therefore declines in Collembola could have large effects on other taxa, suggesting Collembola may be the missing link in producing a bottom-up effect due to invasive plant litter in CSS.

According to bottom-up theory, declines in the most common collembolan families could explain our findings of 
Fig. 5 Responses of native ant species to a 3 year non-native grass litter manipulation. Legend as in Fig. 2; bars mean \pm SE. Arthropod values are the total number of individuals trapped in each growing season adjusted to four traps per plot opened for 8 days (see "Materials and methods" for further details)
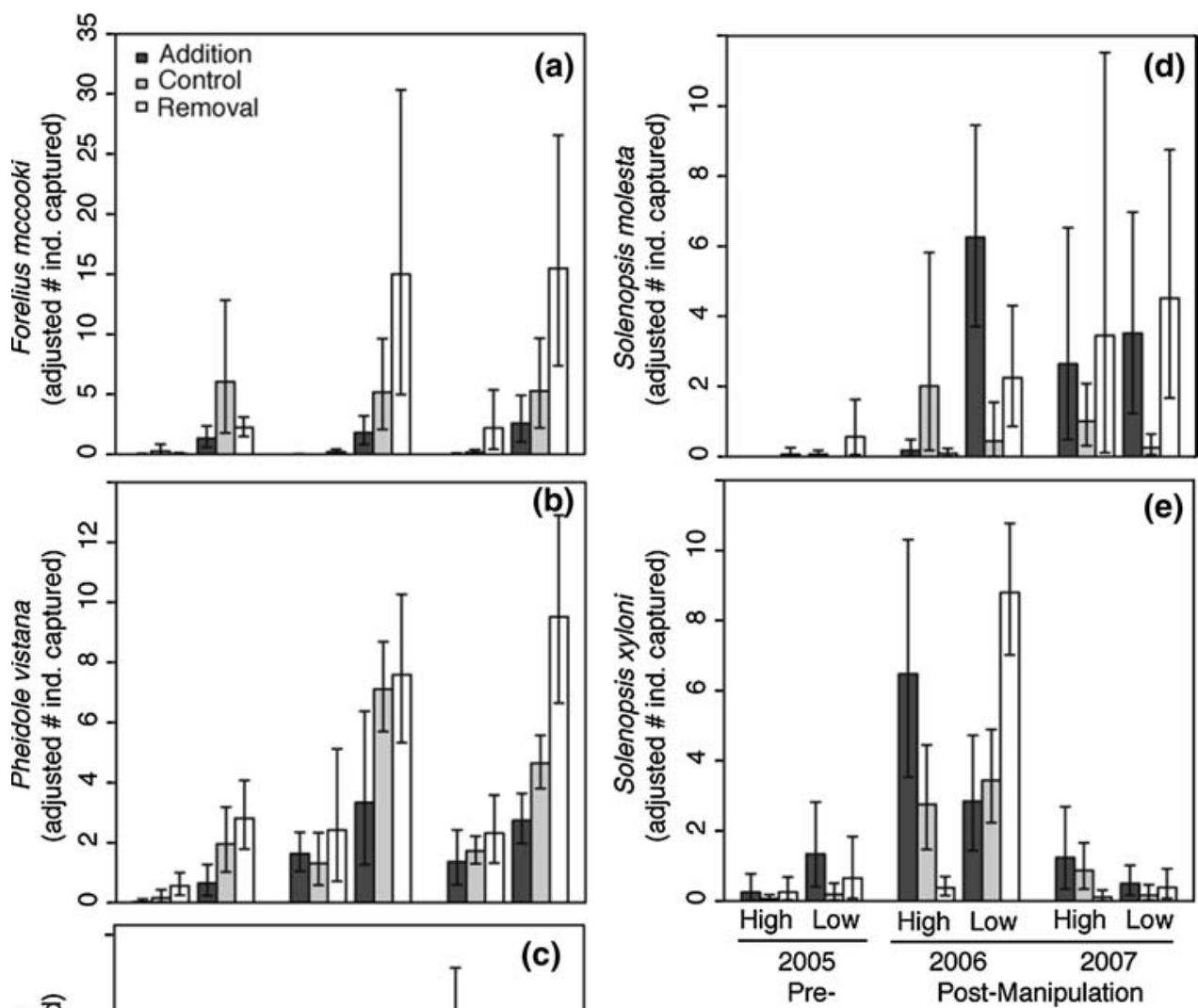

e)

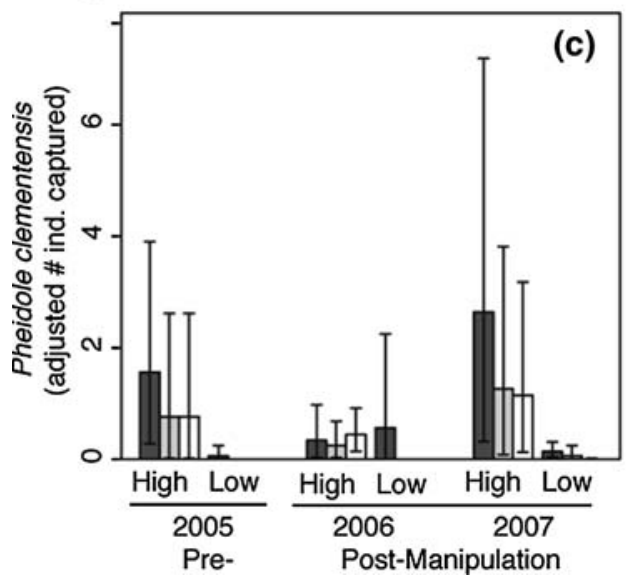

decreased predatory arthropod abundance in areas invaded by non-native grasses; however, responses varied by taxa. All predatory mites (Prostigmata) declined with increased grass invasion, and we linked these responses to invasive grass litter for the most common mite family in particular (Anystidae). Predatory mites of the size we found (1$2 \mathrm{~mm}$ ) generally feed on arthropod eggs or small arthropods, such as Collembola (Dindal 1990); thus if CSS mites specialize on collembolan families common in uninvaded areas, they may decline because of decreased availability of prey resources. In contrast to mites, and to our predictions, we found no consistent responses of spiders and harvestmen to grass invasion or grass litter. This may be due to a variety of reasons including structural changes that increase refugia for spiders from their predators but also make hunting by ground spiders more difficult (Wise 1993).
Additionally the lack of a response may suggest spiders, which are most often generalist feeders, adjust their diets as certain prey items, such as common ant species, decline in abundance.

We found general support for our species-specific predictions regarding different ant taxa. This suggests predictions of arthropod responses to plant invasions may be most robust for taxa, such as ants, that are relatively well described ecologically and have robust species classifications. We documented that generalist species that are not specialized to arid systems appeared unaffected by nonnative grass invasion, while those species confined to arid systems declined in invasion areas. The two Solenopsis species, S. molesta and S. xyloni, have wide geographic ranges (Creighton 1950; P. Ward, personal communication), and S. xyloni is known to have a varied diet, like other 
species of fire ants (Tennant and Porter 1991); they showed no apparent response to non-native grass litter. These results indicate that generalist habits and prey preferences may buffer certain ant species from the effects of plant invasions. The two most common ant species, F. mccooki, and $P$. vistana, declined in areas of high grass invasion. Both are arid system specialists with ranges restricted generally to the US southwest and Baja California (Creighton 1950). While $F$. mccooki is omnivorous (P. Ward, personal communication), $P$. vistana is thought to be largely entomophagous (Wheeler and Wheeler 1986) and thus both ant species may have declined because of reductions in their prey, such as Collembola, or because of structural changes resulting from litter addition. $P$. vistana in particular is a desert species with long legs and may be physically impeded from moving through thick grass thatch. In contrast, declines in $F$. mccooki numbers in areas with grass litter seem to be likely caused by reductions in soil temperatures resulting from the insulating effects of litter. Non-native litter in CSS decreases soil temperature $2.06 \pm 0.61^{\circ} \mathrm{C}$ (Wolkovich et al. 2009), which may be sufficient to limit the activity of thermophilic taxa such as Forelius that are highly tolerant of high temperatures (Hölldobler and Wilson 1990). We did not observe consistent increases for any ant species other than P. clementensis. This seed specialist (Wilson 2003) appeared to benefit, as predicted, from the non-native grass. The lack of any consistent positive response by other ant species is surprising because grass litter increases soil moisture (Wolkovich et al. 2009), which stimulates activity of several native CSS ants including F. mccooki, P. vistana and S. xyloni (Menke and Holway 2007).

Linking arthropod trends to grass invasion and grass litter

Although we documented consistent trends for many taxa in our observational survey of grass invasions, our litter manipulations identified non-native litter as the mechanism for only the two most common taxa (F. mccooki and Anystidae mites). This result may be due to spatial and temporal scaling issues. Our manipulation plot size of $9 \mathrm{~m}^{2}$ is much smaller than the foraging ranges of the ant species encountered (except possibly S. molesta and P. clementensis) and is probably smaller than the foraging areas of the other predators in the system as well, thus larger scale experiments may be required to isolate the effects of grass litter on these taxa. Long-term studies may also be needed to document arthropod and soil impacts of non-native litter; effects of the manipulation on $F$. mccooki were most dramatic 2 years after the manipulation (Fig. 5a) and may have increased further with additional years of study. Finally, the lack of response to the litter manipulation by taxa that showed consistent observational trends with grass invasion could indicate such declines may be due to an underlying factor to which both arthropods and non-native grasses respond, such as soil texture patterns (Didham et al. 2005, 2007).

In addition, effects caused by bottom-up forces may take years to appear for some taxa, especially in a semi-arid system where productivity is pulsed due to rainfall patterns and arthropod numbers vary strongly across years (Fig. 2). Indeed, we found the lowest abundance of arthropods (2005) 1 year after an extremely dry winter (2003-2004) and the highest abundance (2006) 1 year after an extremely wet winter (2004-2005). This may indicate that arthropods show a 1-year lag in response to pulsed productivity, which is common in detritus-based communities (Kappes et al. 2007). Additionally, temperature may play a role in our findings. Although we sampled most years for an average of 12 days each growing season, unusually cool periods may reduce the capture of thermophilic taxa such as ants. While most monthly mean spring temperatures for the years of our study were consistent with the 100-year mean in San Diego, an unusually warm period in the late spring of $2006\left(18.2^{\circ} \mathrm{C}\right.$ versus the average of $17.4^{\circ} \mathrm{C}$ for May and $21.5^{\circ} \mathrm{C}$ versus $18.8^{\circ} \mathrm{C}$ for June, data from Western Region Climate Center) could also have contributed to increased arthropod numbers in 2006.

Implications for CSS and other invaded systems

Declines in the two most common native ants, F. mccooki and $P$. vistana, in areas of high non-native grass are a particular concern in CSS. Along moisture-rich habitats (urban edges, riparian zones and seasonal stream flow through canyons), Argentine ants (L. humile) invade and are associated with strong declines of most native ant species (Holway 2005; Suarez et al. 1998). Large reserve interiors, such as those where this study was conducted, provide most of the remaining CSS habitat for $F$. mccooki and P. vistana. Thus, if natural areas become heavily invaded with non-native grasses, common ant species may exhibit region-wide declines. Because $F$. mccooki and P. vistana represented $38-70 \%$ of all ants across our 4 years of sampling, they are likely key components of the ground arthropod food webs in CSS ecosystems. Ants are the main prey for many lizards in this habitat (Suarez and Case 2002; Suarez et al. 2000), and across many systems are considered bioindicators and ecosystem engineers (Andersen and Majer 2004; Folgarait 1998; Meysman et al. 2006). As engineers, ants may influence soil development by mixing the soil profile (Torn et al. 1997). Additionally, Forelius is a numerically dominant genus in the southwestern United States (Sanders et al. 2007), and its decline may indicate overall decline in the habitat for other ant species (Andersen and Majer 2004).

Our work highlights the importance of litter produced by invasive plants on ground arthropods and microbial 
assemblages. The literature on bottom-up effects has generally ignored the role of detritus, especially in terrestrial systems. Recently, however, work focused on microbial impacts (Klironomos 2002; Wolfe and Klironomos 2005) and impacts further up the detrital-based web (Halaj and Wise 2002; Scheu and Schaefer 1998; Wise 2006), has demonstrated the importance of detritus for microbial and arthropod communities. We advanced this field of study by showing how invasive plant detritus can alter microbial and arthropod communities. We found that fungal biomass but not arthropod numbers were greater in areas of high nonnative litter cover. Because fungi are a basal resource for many ground arthropod taxa (Coleman and Crossley 2003; Wardle 2002), understanding how non-native litter alters pathways between microbes and arthropods is of clear importance.

Finally, short-term (2 years) responses in the two most common arthropod taxa (F. mccooki and Anystidae mites) to litter removal demonstrate the value of thatch removal as a management regime. Removal of grass thatch is a common management technique throughout the southwest United States to reduce invasive grass cover and fire risk (Meyer and Schiffman 1999). Our results support it as a restoration technique to also effectively enhance native ground arthropod communities.

Acknowledgments We wish to thank K. Gregory and T. Prentice for expert assistance in identifying mites and spiders (respectively), $\mathrm{P}$. Ward for expert assistance in Californian ant species information and identification, S. Hellmuth and J. Butzler for field help, and M. Nathan and Brit Ousterhout for lab help. Two anonymous reviewers, K. Cottingham, M. Ayres and J.C. Moore greatly improved earlier versions of this manuscript. Funding was provided by UC IPM Exotic/Invasive Pests and Diseases Research Program, Center for Invasive Plant Management, EPA's STAR (EMW) program, NSF grant DEB-0316798 (DTB), US Department of Agriculture (NRI-CGP 2006-35302-17255) (DAH), and Dartmouth's Arts and Sciences Alumni grant, Cramer Fund. The authors declare all research described here complied with all current laws of the United States.

Open Access This article is distributed under the terms of the Creative Commons Attribution Noncommercial License which permits any noncommercial use, distribution, and reproduction in any medium, provided the original author(s) and source are credited.

\section{References}

Andersen AN (1997) Functional groups and patterns of organization in North American ant communities: a comparison with Australia. J Biogeogr 24:433-460

Andersen AN, Majer JD (2004) Ants show the way down under: invertebrates as bioindicators in land management. Front Ecol Environ 2:291-298

Anderson MJ (2001) Permutation tests for univariate or multivariate analysis of variance and regression. Can J Fish Aquat Sci 58:626-639

Barbour MG, Burk JH, Pitts WD, Gilliam FS, Schwartz MW (1999) Terrestrial plant ecology, 3rd edn. Cummings, Menlo Park
Bolger DT, Suarez AV, Crooks KR, Morrison SA, Case TJ (2000) Arthropods in urban habitat fragments in southern California: area, age, and edge effects. Ecol Appl 10:1230-1248

Box GEP (1954) Some theorems on quadratic forms applied in the study of analysis of variance problems.1. Effect of inequality of variance in the one-way classification. Ann Math Stat 25:290302

Cione NK, Padgett PE, Allen EB (2002) Restoration of a native shrubland impacted by exotic grasses, frequent fire, and nitrogen deposition in southern California. Restor Ecol 10:376-384

Coleman DC, Crossley DA (2003) Fundamentals of soil ecology. Academic, Boston

Creighton WS (1950) The ants of North America. Bull Museum Comp Zool Harv Univ 104:1-585

Curtis DJ (1980) Pitfalls in spider community studies (Arachnida, Araneae). J Arachnol 8:271-280

Didham RK, Tylianakas JM, Hutchinson MA, Ewers RM, Gemmell NJ (2005) Are invasive species the drivers of ecological change? Trends Ecol Evol 20:470-474

Didham RK, Tylianakis JM, Gemmell NJ, Rand TA, Ewers RM (2007) Interactive effects of habitat modification and species invasion on native species decline. Trends Ecol Evol 22:489-496

Dindal DL (1990) Soil biology guide. Wiley, New York

Ernst CM, Cappuccino N (2005) The effect of an invasive alien vine, Vincetoxicum rossicum (Asclepiadaceae), on arthropod populations in Ontario old fields. Biol Invasions 7:417-425

Folgarait PJ (1998) Ant biodiversity and its relationship to ecosystem functioning: a review. Biodivers Conserv 7:1221-1244

Gill RW (1969) Soil microarthropod abundance following old-field litter manipulation. Ecology 50:805-816

Gratton C, Denno RF (2005) Restoration of arthropod assemblages in a Spartina salt marsh following removal of the invasive plant Phragmites australis. Restor Ecol 13:358-372

Gratton C, Denno RF (2006) Arthropod food web restoration following removal of an invasive wetland plant. Ecol Appl 16:622-631

Gregg RE (1969) New species of Pheidole from Pacific Coast islands (Hymenoptera: Formicidae). Entomol News 80:93-101

Halaj J, Wise DH (2002) Impact of a detrital subsidy on trophic cascades in a terrestrial grazing food web. Ecology 83:3141-3151

Hölldobler B, Wilson EO (1990) The ants. Belknap/Harvard University Press, Cambridge

Holway DA (2005) Edge effects of an invasive species across a natural ecological boundary. Biol Conserv 121:561-567

Holway DA, Suarez AV, Case TJ (2002) Role of abiotic factors in governing susceptibility to invasion: a test with argentine ants. Ecology 83:1610-1619

Hunt HW, Wall DH (2002) Modelling the effects of loss of soil biodiversity on ecosystem function. Glob Change Biol 8:33-50

Hunt HW et al (1987) The detrital food web in a shortgrass prairie. Biol Fertility Soils 3:57-68

Ingham ER, Trofymow JA, Ames RN, Hunt HW, Morley CR, Moore JC, Coleman DC (1986a) Trophic interactions and nitrogen cycling in a semiarid grassland soil.1. Seasonal dynamics of the natural-populations, their interactions and effects on nitrogen cycling. J Appl Ecol 23:597-614

Ingham ER, Trofymow JA, Ames RN, Hunt HW, Morley CR, Moore JC, Coleman DC (1986b) Trophic interactions and nitrogen cycling in a semiarid grassland soil. 2. System responses to removal of different groups of soil microbes or fauna. J Appl Ecol 23:615-630

Kappes H, Lay R, Topp W (2007) Changes in different trophic levels of litter-dwelling macrofauna associated with giant knotweed invasion. Ecosystems 10:734-744

Keeley JE, Baer-Keeley M, Fotheringham CJ (2005) Alien plant dynamics following fire in Mediterranean-climate California shrublands. Ecol Appl 15:2109-2125 
Klironomos JN (2002) Feedback with soil biota contributes to plant rarity and invasiveness in communities. Nature 417:67-70

Lensing JR, Todd S, Wise DH (2005) The impact of altered precipitation on spatial stratification and activity-densities of springtails (Collembola) and spiders (Araneae). Ecol Entomol 30:194-200

Liao CZ et al (2008) Altered ecosystem carbon and nitrogen cycles by plant invasion: a meta-analysis. New Phytol 177:706-714

Longcore TR (1999) Terrestrial arthropods as indicators of restoration success in coastal sage scrub. PhD, Department of Geography, University of California, Los Angeles

Mack RN, Simberloff D, Lonsdale WM, Evans H, Clout M, Bazzaz FA (2000) Biotic invasions: causes, epidemiology, global consequences, and control. Ecol Appl 10:689-710

Menke SB, Holway DA (2006) Abiotic factors control invasion by Argentine ants at the community scale. J Anim Ecol 75:368-376

Meyer MD, Schiffman PM (1999) Fire season and mulch reduction in a California grassland: a comparison of restoration strategies. Madroño 46:25-37

Meysman FJR, Middelburg JJ, Heip CHR (2006) Bioturbation: a fresh look at Darwin's last idea. Trends Ecol Evol 21:688-695

Minnich RA, Dezzani RJ (1998) Historical decline of coastal sage scrub in the Riversie-Perris Plain, California. Western Birds 29:366-391

Mooney HA (1977) Southern coastal scrub. In: Major J (ed) Terrestrial vegetation of California. Wiley, New York, pp 471-489

Moya-Larano J, Wise DH (2007) Direct and indirect effects of ants on a forest-floor food web. Ecology 88:1454-1465

O'Dowd DJ, Green PT, Lake PS (2003) Invasional 'meltdown' on an oceanic island. Ecol Lett 6:812-817

Oksanen L, Fretwell SD, Arruda J, Niemela P (1981) Exploitation ecosystems in gradients of primary productivity. Am Nat 118:240-261

Perner J, Schueler S (2004) Estimating the density of ground-dwelling arthropods with pitfall traps using a nested-cross array. J Anim Ecol 73:469-477

Polis GA, Strong DR (1996) Food web complexity and community dynamics. Am Nat 147:813-846

Prentice TR, Burger JC, Icenogle WR, Redak RA (1998) Spiders from Diegan coastal sage scrub (Arachnida: Araneae). Pan Pacific Entomol 74:181-202

Retana J, Cerda X (2000) Patterns of diversity and composition of Mediterranean ground ant communities tracking spatial and temporal variability in the thermal environment. Oecologia 123:436-444

Sakai AK, Allendorf FW, Holt JS, Lodge DM, Molofsky J, With KA, Baughman S, Cabin RJ, Cohen JE, Ellstrand NC, McCauley DE, O'Neil P, Parker IM, Thompson JN, Weller SG (2001) The population biology of invasive species. Annu Rev Ecol Syst 32:305332

Sanders D, Platner C (2007) Intraguild interactions between spiders and ants and top-down control in a grassland food web. Oecologia 150:611-624

Sanders NJ, Weltzin JF, Crutsinger GM, Fitzpatrick MC, Nuñez MA, Oswalt CM, Lane KE (2007) Insects mediate the effects of propagule supply and resource availability on a plant invasion. Ecology 88:2383-2391
Scheu S, Schaefer M (1998) Bottom-up control of the soil macrofauna community in a beechwood on limestone: manipulation of food resources. Ecology 79:1573-1585

Schoenherr AA (1992) Cismontane Southern California. In: Schoenherr AA (ed) A natural history of California. University of California Press, Berkeley, pp 313-405

Suarez AV, Case TJ (2002) Bottom-up effects on persistence of a specialist predator: ant invasions and horned lizards. Ecol Appl 12:291-298

Suarez AV, Bolger DT, Case TJ (1998) Effects of fragmentation and invasion on native ant communities in coastal southern California. Ecology 79:2041-2056

Suarez AV, Richmond JQ, Case TJ (2000) Prey selection in horned lizards following the invasion of Argentine ants in southern California. Ecol Appl 10:711-725

R Development Core Team (2007) R: a language and environment for statistical computing. In: R foundation for statistical computing, Vienna

Tennant LE, Porter SD (1991) Comparison of diets of two fire ant species (Hymenoptera: Formicidae): solid and liquid components. J Entomol Sci 26:450-465

Torn MS, Trumbore SE, Chadwick OA, Vitousek PM, Hendricks DM (1997) Mineral control of soil organic carbon storage and turnover. Nature 389:170-173

Ward PS (2005) A synoptic review of the ants of California (Hymenoptera: Formicidae). Zootaxa 936:1-68

Wardle DA (2002) Communities and ecosystems: linking the aboveground and belowground components. Princeton University Press, Princeton

Wardle DA, Bonner KI, Barker GM, Yeates GW, Nicholson KS, Bardgett RD, Watson RN, Ghani A (1999) Plant removals in perennial grassland: vegetation dynamics, decomposers, soil biodiversity, and ecosystem properties. Ecol Monogr 69:535-568

Wardle DA, Bardgett RD, Klironomos JN, Setala H, van der Putten WH, Wall DH (2004) Ecological linkages between aboveground and belowground biota. Science 304:1629-1633

Wheeler GC, Wheeler JN (1986) The ants of Nevada. Natural History Museum of Los Angeles County, Los Angeles

Wilson EO (2003) Pheidole in the new world: a dominant hyperdiverse ant genus. Harvard University Press, Cambridge

Wise DH (1993) Spiders in ecological webs. Cambridge University Press, New York

Wise DH (2006) Cannibalism, food limitation, intraspecific competition and the regulation of spider populations. Annu Rev Entomol $51: 441-465$

Wolfe BE, Klironomos JN (2005) Breaking new ground: soil communities and exotic plant invasion. Bioscience 55:477-487

Wolfinger RD (1996) Heterogeneous variance: covariance structures for repeated measures. J Agric Biol Environ Stat 1:205-230

Wolkovich EM (2009) Non-native grass litter enhances grazing arthropod assemblages by increasing native shrub growth. Ecology (in press)

Wolkovich EM, Lipson DA, Virginia RA, Bolger DT, Cottingham KL (2009) Grass invasion causes rapid increases in ecosystem carbon and nitrogen storage in a semi-arid shrubland. Glob Change Biol (in press) doi:10.1111/j.1365-2486.2009.02001.x 